\title{
Study on Team Stability Based on the Perspective of Knowledge Potential*
}

\author{
Yi Huang, Jinfu Ye, Zhi Gao
}

Knowledge of Management, Northwestern Polytechnical University, Xi'an, China.

Email: dxx9664@126.com,yjf@nwpu.edu.cn, dazhi1217@163.com

Received May $24^{\text {th }}, 2012$; revised June $24^{\text {th }}, 2012$; accepted July $24^{\text {th }}, 2012$

\begin{abstract}
Based on the knowledge potential, we analyze the stability of team. Using Logistic rule simulation knowledge of alliance competition process, we draw stable solution of knowledge shift in the team; through the system MATLAB simulation, it shows that stability of team has something to do with length of cooperation. Research results can provide reference for promoting the stability of team and internal knowledge sharing.
\end{abstract}

Keywords: Knowledge Potential; Stability; Knowledge Shift; Team

\section{Introduction}

In modern society, high pressure fills market environment and global economy. Knowledge has become the key of economy resources as well as the dominant source of competitive edge. It is necessary to explore effectively the members' knowledge position, to achieve the individual knowledge shift in research team. Thus improving innovative level and promoting exploratory speed, which will play a crucial role in new products exploitation. On account of the members in workgroup who has satisfy the senior professional knowledge technical skills, which means they can keep the initiative in their own hands to a great extent; concurrently, the innovation is very important in their job, furthermore quick rhythm and high stress. They bring up an instability situation in workgroup between individuality and entirety; otherwise it would exert adverse influence on information interchanged in workgroup.

Nowadays, Zhou Na [1], Zhou Mi [2] have been doing research in this region, also they have made a great deal of efforts doing practice research in personal relationship. In other ways, previously, the research about information transfer of individuality and entirety always focuses on conciseness, avoiding duplication and originality, the point of view of research focuses on drifted mechanism and procedure, emphasizes emphatically individual characteristic, for instances personal skills, knowledge and aspiration, the feature of knowledge, the social relations of two parties and its influence on knowledge transfer, nevertheless, some researches were found in relationship be-

\footnotetext{
*This research was supported by Fund of the China Shang Fei company
} management innovation mode research under grant NAEK0001. tween team and personality when transference is completed. It is an overwhelming major circumstance in contemporary time that the individuality acquires knowledge from internal team, thus he can promote personal competition, in this process, individual would not be satisfied with the existing team, therefore they would select other team to cooperate, on this occasion they pose a threat to stable relationship between individual and entirety, the team eventually would disintegrate. That is the major impediment to transfer knowledge in internal team. The views on individual, adoption of the new environment would expend a great deal of time and energy, meanwhile it would have negative influence on knowledge transference in the scope of team. The research by Wei Jiang [3] demonstrated that knowledge position leads to knowledge transference in internal team, therefore, it can improve the team's stability. Nonetheless, the general research is not concentrated on "how the knowledge position influences over knowledge team's stability".

From the above, based on the angle of knowledge position, this article is to analyze knowledge shared situation in knowledge team, which includes different knowledge position individual in principal knowledge, to investigate how it can preserve the stable and permanent relationship of team by main part of knowledge, and improve stability in knowledge team.

\section{The Theory of the Knowledge Position}

Polanyi (1967) separated knowledge which "tacit knowledge" and "explicit knowledge" based on the knowledge pattern. Inside, explicit knowledge means being capable of encoding, which can be illustrated by text, data, for- 
mula, specification, brochure and number; tacit knowledge means based on persons, being not able to encode, difficult to obtain by normal approach. From one of subdivision and profession technical region, the knowledge quality and number by knowledge subject were different in strategy union, for that reason, comparative "advantage individual" and "disadvantage individual" both exist.

Advantage knowledge position demonstrates the depth and extent of knowledge in enterprise, furthermore, the depth and width of knowledge illustrate a great deal of knowledge stock, which means formidable power of competition. Chen Feixiang [4] and others introduce physical concept (potential energy, potential difference, energy transform) to research of knowledge diffusion, Chen regards the persons who possess advantage knowledge as an entirety. They were originally spreading sources in knowledge diffusion theory. Li Li [5] made a deep investigation and study in the relation between knowledge position and knowledge diffusion based on the net environment, Li regards the knowledge diffusion by knowledge subject mainly influence their internal knowledge region (knowledge depth (KD) and knowledge width $(\mathrm{KW})$ ). Therefore, taking account of discrepancy of knowledge width and depth would result in knowledge location, consequently knowledge always moves from advantage position to disadvantage position.

Advantage object considers out of individual profit. They were not willing to share knowledge with disadvantage object. Yang Xun and Shi Ping [6] were investigated the tacit knowledge spreading conditions and activation by employee, investigation indicates the key to spread knowledge were aspiration and ability by advantage knowledge object. Tao Houyong and Liu Hong [7] provided that through sharing mechanism, knowledge can achieve connection among advantage object, disadvantage object and organization environment, nevertheless, distinct sharing mechanism results in different effect, thence shall construct reasonable sharing mechanism on their individual pattern, bring knowledge sharing initiative into effect, promote the effect of knowledge sharing and achieve maximum group profit. The knowledge object in strategic league can be regarded as a mixture by knowledge position from variable region, different regions consist of dissimilar knowledge position, otherwise the knowledge object perhaps is provider (advantage) or receiver (disadvantage) in particular region. The Figures 1(a) and (b) provided that when a team is a member, choose his partner. The ordinary selection is based on knowledge position to take effective measures. Reasonable potential difference, equitable knowledge sharing, which can foster knowledge connection and innovation, furthermore improve whole efficiency and are beneficial
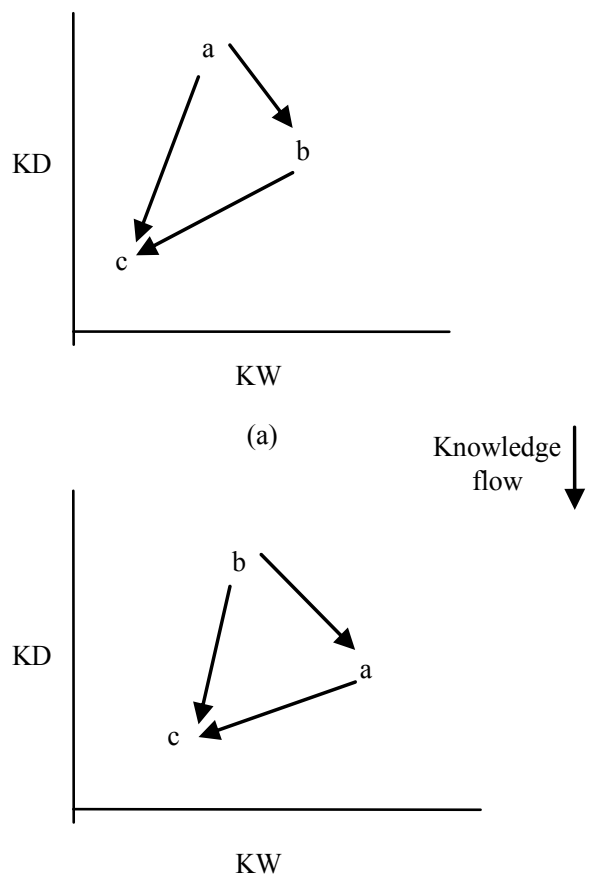

(b)

Figure 1. (a) Team A; (b) Team B.

for constructing stable knowledge league. Whether the knowledge sharing was overheated, it will cause opportunism, the advantage objects outflow eventually their central knowledge, to decline team's competition; otherwise, whether the knowledge sharing was insufficient, it will result in competitive learning ability and additional purchase, thence the league's productiveness can not be realized, eventually disintegrate the team. Consequently, how to conduct shared knowledge with colleague as well as grasp the certain extent, this is mainly based on team's stability. Therefore, in this article it would draw support from the members of mathematical analysis team. To explore the process of competition and cooperation in their knowledge transference, therefore, discover the method to maintain stable team from it.

\section{Modeling and Simulation}

\subsection{Logistic Rule}

In nature, if only a biological community survive, people commonly choose Logistic model to describe the species of the evolution process of the population, namely

$$
x(t+1)=r x(t)\left(1-\frac{x(t)}{N}\right)
$$

$x(t)$ is the number of species. $r$ is inherent growth rate. $N$ is the environment resources allowing the biggest population quantity. The following of this paper will use 
a Logistic research on individual and team stability.

\subsection{Model Construction}

Generally, individuals have a strong dependence on the team, a good team can accelerate the development of individuals, and a bad team can have the opposite effect on the individuals. Therefore, the team and individual can not exist with interdependence. However, due to the external environment changes and fierce competition, the number of individuals to the knowledge of the team ensures the stability of the team and individuals to develop it. Here we are on this issue being discussed by the mathematical model.

A set body of knowledge can exist independently, his knowledge of the stock increased in accordance with the laws Logistic, B is the body of knowledge providing a body of knowledge A knowledge of the stock, the body of knowledge helping the growth of A's stock of knowledge, knowledge, knowledge of the main A increase the stock of the knowledge we can write

$$
x_{1}(t+1)=r_{1} x_{1}(t)\left(1-\frac{x_{1}(t)}{N_{1}}+s_{1}^{\prime} \frac{x_{2}(t)}{N_{2}}\right)
$$

$r_{1}\left(r_{1}\right.$ as $x_{1}(t)$ is intrinsic growth rate of the stock of knowledge), $N_{1}, N_{2}\left(N_{1}, N_{2}\right.$ is A, B of the largest stock of knowledge), the mean of $s_{1}^{\prime}$ is knowledge of the main body of knowledge A, which is supplied stock of knowledge by $\mathrm{B}$, that is $s_{1}^{\prime}$ times for A knowledge of the main body of knowledge supply consumed the stock of knowledge A. $s_{2}$ A supply B of the stock knowledge is $s_{2}$ that the stock of knowledge consumed by B.

Knowledge of $\mathrm{B}$ will perish without knowledge of the main A, The mortality rate is set as $r_{2}^{\prime}$

$$
x_{2}(t+1)=-r_{2}^{\prime} x_{2}(t)
$$

Knowledge A provides knowledge to the knowledge B. The right of Equation (1) plus the growth knowledge of A promotes B get

$$
x_{2}(t+1)=r_{2}^{\prime} x_{2}(t)\left(-1+s_{2}^{\prime} \frac{x_{1}(t)}{N_{1}}\right)
$$

only when $s_{2} \frac{x_{1}(t)}{N_{1}}>1$, the stock of knowledge that the number of the knowledge B will only increase, and have competitive, and at the same time the stock of the knowledge B growth, will be affected by their own block function, so the Equation (3) will become

$$
x_{2}(t+1)=r_{2}^{\prime} x_{2}(t)\left(-1+s_{2} \frac{x_{1}}{N_{1}}-\frac{x_{2}}{N_{2}}\right)
$$

Simultaneous Equation (3) and Equation (4) get equations

$$
\left\{\begin{array}{l}
x_{1}(t+1)=r_{1} x_{1}(t)\left(1-\frac{x_{1}(t)}{N_{1}}+s_{2}^{\prime} \frac{x_{2}(t)}{N_{2}}\right) \\
x_{2}(t+1)=r_{2}^{\prime} x_{2}(t)\left(-1+s_{2} \frac{x_{1}}{N_{1}}-\frac{x_{2}}{N_{2}}\right)
\end{array}\right.
$$

Through analysis balance, discuss after long enough time, two of the main body of knowledge change trend. From Table 1 we can see stable point $p_{2}$, A and $\mathrm{B}$ can depend on each other's symbiosis.

\subsection{Analog Emulation}

According to the study, we have hypothesis that $x_{1}=0.1$. $x_{2}=0.1, r_{1}=2.5, r_{2}=1.8, N_{1}=1.6, N_{2}=1, p_{1}, p_{2}$, respectively assign $s_{1}, s_{2}$. Use of MATLAB simulation subject knowledge the stock of knowledge that the changes with time trend.

Through Figures $\mathbf{2}$ and $\mathbf{3}$ research we can see, knowledge is a main body organization, individual came into the organization, in the stock of knowledge that the team will be significantly reduced. After a period of time, the team will constantly pick up knowledge, but in some

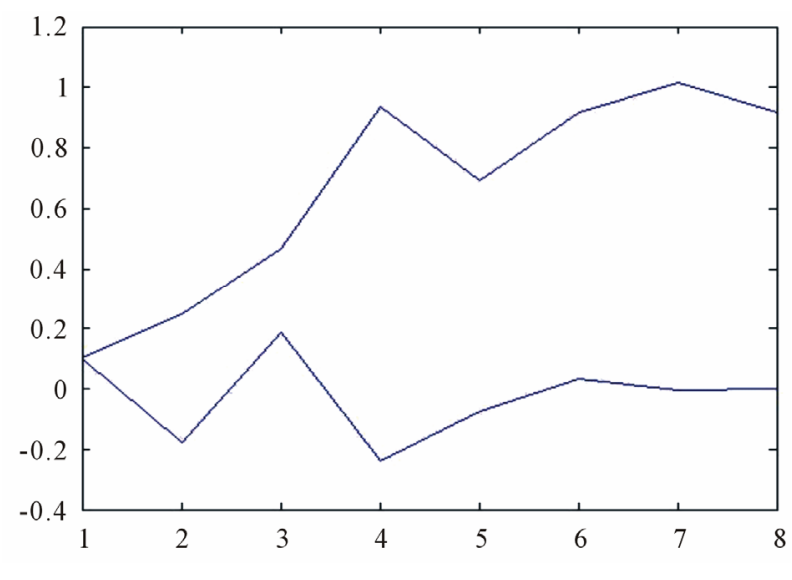

Figure 2. $s_{1}^{\prime}=0.5, s_{2}=1.6$.

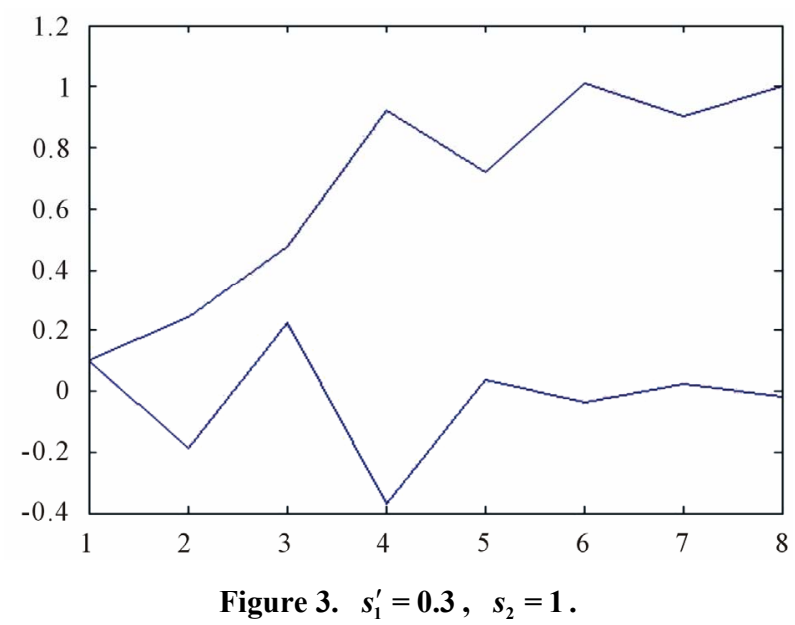


Table 1. A and B stable solution.

\begin{tabular}{cccc}
\hline Balance & $\boldsymbol{P}$ & $\boldsymbol{q}$ & Stability conditions \\
\hline$p_{1}\left(N_{1}, 0\right)$ & $r_{1}-r_{2}^{\prime}\left(s_{2}-1\right)$ & $-r_{1} r_{2}^{\prime}\left(s_{2}-1\right)$ & $s_{2}<1, s_{1}^{\prime} s_{2}<1$ \\
$p_{2}\left(\frac{N_{1}\left(1-s_{1}^{\prime}\right)}{1-s_{1}^{\prime} s_{2}}, \frac{N_{2}\left(s_{2}-1\right)}{1-s_{1}^{\prime} s_{2}}\right)$ & $\frac{r_{1}\left(1-s_{1}^{\prime}\right)+r_{2}^{\prime}\left(s_{2}-1\right)}{1-s_{1}^{\prime} s_{2}}$ & $\frac{r_{1} r_{2}^{\prime}\left(1-s_{1}^{\prime}\right)\left(s_{2}-1\right)}{1-s_{1}^{\prime} s_{2}}$ & $s_{1}^{\prime}<1, s_{2}>1, s_{1}^{\prime} s_{2}<1$ \\
$p_{3}(0,0)$ & $-r_{1}+r_{2}^{\prime}$ & $-r_{1} r_{2}^{\prime}$ & Unstable \\
\hline
\end{tabular}

period, the rapid growth of the personal knowledge becomes very fast. Stock of team knowledge, begins to drop constantly. Because of people in the whole team slowly began to absorb the knowledge of operation and this is the second peak time. So we can see the relationship between team and individual, there will be two times for absorbing the knowledge of the peak. The two peaks will enhance the stock of the individual knowledge. After the stock of the individual and team knowledge that will also begin to increase. In the two times of individual rapid knowledge absorbing from the team, and it is the time for individual to grow faster. The internal culture of concept is formed by the organization and the individual also is the fastest absorption. So this time the organization shall intensify the personal training, make people more quickly into the organization of the atmosphere, and promote organization knowledge transfer efficiency.

\section{Conclusions}

In this paper, Logistic principle is made use of simulating the competition and cooperation process, and the knowledge sharing stable solution is obtained; meanwhile, it is proved that there is some connection between team stability and time through system simulation and algorithm calculation.

Team stability is improved by improvement of team knowledge transfer, the next step of research, quantitative research will be done on factors of algorithm based on demonstration.

\section{REFERENCES}

[1] N. Zhou and J. A. Zhong, "Team Difference and Personal Innovation Behavior: Adjust Dependence as Variab," Understand Science of China, Vol. 17, No. 1, 2007, pp. $27-$ 30 .

[2] M. Zhou, X. P. Zhao and W. Li, "Individual and Team Performance Related Knowledge Transfer Effect, Team Performance Relations," Intelligence Magazine of China, Vol. 12, No. 12, 2006, pp. 24-27.

[3] J. Du and J. Wei, "The Stock of Knowledge Increasing Mechanism Analysis," Understand Science of China, Vol. 10, No. 7, 2004, pp. 24-27.

[4] F. X. Chen, L. Zhang and J. Hu, "Knowledge Diffusion, the Establishment of the Field and Empirical Analysis," Studies in Science of China, Vol. 23, No. 2, 2005, pp. 253-257.

[5] L. Li, X. H. Dang and S. K. Zhang, "Based on the Knowledge of the Potential of the Technology Innovation Cooperation Study Knowledge Diffusion," Understand Science of China, Vol. 14, 2007, pp. 20-26.

[6] X. Yang and P. Shi, "Staff Personal Knowledge Diffusion Conditions and Incentive," Journal of Ocean University of China, Vol. 20, No. 4, 2005, pp. 50-53.

[7] H. Y. Tao and H. Liu, "Knowledge Sharing Mechanism of Group Study on the Impact of Performance," Scientific Research Management of China, Vol. 29, No. 3, 2008, p. 53. 